\title{
Comparison of the antioxidant effects of carnosic acid and synthetic antioxidants on tara seed oil
}

\author{
Zhan-jun Li ${ }^{1,2}$, Feng-jian Yang ${ }^{1 *}$, Lei Yang ${ }^{1}$ and Yuan-gang Z $\mathrm{u}^{1}$
}

\begin{abstract}
Background: In the present study, tara seed oil was obtained by supercritical fluid extraction and used to investigate the antioxidant strength of carnosic acid (CA) compared with conventional synthetic antioxidants.

Methods: The antioxidants were added to the tara seed oil at $0.2 \mathrm{mg}$ of antioxidant per gram of oil. The samples were then submitted to at $60^{\circ} \mathrm{C} 15$ days for an accelerated oxidation process, with samples taken regularly for analysis. After oxidation, the samples were analyzed to determine the peroxide value, thiobarbituric acid reactive substances, conjugated diene content, and free fatty acid content. CA was investigated at three purity levels (CA20, CA60, CA99), and compared with three synthetic antioxidants (butylatedhydroxyanisole, butylatedhydroxytoluene, and tert-butylhydroquinone).

Results: The oxidation indicators showed that CA was a strong antioxidant compared to the synthetic antioxidants. The antioxidant activities decreased in the order: tert-butylhydroquinone > CA99 > CA60 > CA20 > butylatedhydroxyanisole $>$ butylatedhydroxytoluene. These results show that CA could be used to replace synthetic antioxidants in oil products, and should be safer for human consumption and the environment.
\end{abstract}

Keywords: Carnosic acid, Tara seed oil, Antioxidant, Oxidative stability

\section{Introduction}

As an important plant tannis, tara (Caesalpiniaspinosa) is a kind of precious tree which represents significantly economic benefit, ecological benefit and social benefit. Besides, oil extracted from tara seeds has high content of unsaturated fatty acids. In recent years, it has received extensive attention among researchers [1]. The eight major fatty acids in tara seed oil are palmitic acid, palmitoleic acid, stearic acid, oleic acid, linoleic acid, arachidonic acid, linolenic acid, and behenic acid. The dominant unsaturated fatty acids are linoleic acid, oleic acid, behenic acid, and linolenic acid with contents of $65.36 \%, 13.33 \%, 2.30 \%$ and $0.99 \%$, respectively [2, 3]. Its comprehensive exploitation and utilization is relatively low and correlation studiesand reports are rarely seen,

\footnotetext{
*Correspondence: yangfi@nefu.edu.cn

${ }^{1}$ Key Laboratory of Forest Plant Ecology, Ministry of Education, Northeast Forestry University, Harbin 150040, China

Full list of author information is available at the end of the article
}

so tara can be studied and developed deeply as an energy plant.

To date, some research has been conducted on tara seed oil and its applications, but this area of research is still in its infancy. The unsaturated double bonds in tara seed oil are sensitive, the unsaturated double bonds present in the fatty acids of tara oil are sensitive to oxidation, which may affect the overall quality of the oil $[4,5]$. Exposure of tara seed oil to high temperatures and light can result in oxidation and increase the peroxide value (PV), which makes the oil unpalatable $[6,7]$. The PV is an indicator of the peroxide content and degree of oxidization of an oil. It can be used to determine the degree of lipid oxidation and deterioration, and is mainly used to measure the formation of lipid oxidation products in initial stages of oxidation. It provides a measure of the degree of oil rancidity, and a higher PV is generally indicative of a higher the degree of rancidity. High temperatures and exposure to light are known to promote peroxide 
formation $[8,9]$. The oil is then not beneficial for human consumption because of its rancidity, and increased content of free radicals that are produced by oxidation [1013]. Tara seed oil with a higher content of unsaturated fatty acids, especially polyunsaturated fatty acids, is more susceptible to oxidation than oil with a lower content of unsaturated fatty acids [14]. Oxidation of lipids in oils can produce rancid odors, unpleasant flavors, and discoloration, and also decrease the nutritional quality and safety because the resulting degradation products can have harmful effects on human health $[15,16]$.

Oxidation can occur during oil storage and transportation, and the addition of appropriate antioxidants can inhibit free radical generation and stop rancidification [17]. Currently, the most commonly used type of antioxidants are synthetic ones such as (BHA), (BHT), and (TBHQ) [18]. Studies have shown that these synthetic antioxidants can have differing degrees of toxicity in humans, and can affect the liver, spleen, and lungs [19-21].

The antioxidant strength of a compound can be evaluated by investigating its effect on a number of oxidation indicators, including PV, thiobarbituric acid reactive substances (TBARS), conjugated diene (CD) content, and free fatty acid (FFA) content. In the present study, the antioxidant abilities of carnosic acid (CA) and the synthetic antioxidants BHA, BHT, and TBHQ in tara seed oil were compared. Carnosic acid is a phenolic (catecholic) diterpene, endowed with antioxidative and antimicrobial properties. These results provide a theoretical basis for application of CA to preservation of oils during storage and transportation.

\section{Materials and methods Materials}

Refined, bleached, and deodorized tara seed oil was obtained by Supercritical Fluid Extraction from tara powder (60 mesh) prepared from fresh tara seeds (Wonderful variety) that were collected from Yunnan Province, China in September, 2014. The $\alpha$-tocopherolactalso also as an antioxidant, which content was very low $(<4.3 \mathrm{mg}$ $\mathrm{kg}-1$ ), and the oil contained no synthetic antioxidants, all reagents and solvents were either of HPLC or analytical grade. BHA, BHT, TBHQ, Folin-Ciocalteu reagent, gallic acid standard, catechin standard, and free radicals, and CA were purchased from Sigma-Aldrich Co. (St. Louis, MO, USA).

\section{Preparation of oil}

Fresh tara seeds were dried in an oven at $45^{\circ} \mathrm{C}$ to constant mass, and then ground into powder (60 mesh). Oil was extracted from the powder using supercritical fluid extraction under the following conditions: extraction time $120 \mathrm{~min}$, extraction temperature $45^{\circ} \mathrm{C}$, and extraction pressure $35 \mathrm{MPa}, \mathrm{CO}_{2}$ was the only fluid used.

$110 \mathrm{~mL}$ of tara oil were placed in $125-\mathrm{mL}$ browncolored reagent bottles with narrow necks. The bottles were divided into seven groups, with each group containing three bottles for replication of the experiments. One group of bottles was designated as the blank controls, and CA of different purity (CA20, CA60, and CA99) was added to the first group experiment with three differents bottles at $0.2 \mathrm{mg}$ of CA per gram of oil. The other six groups experiments were designated as synthetic antioxidant groups, and BHA, BHT, TBHQ were added at $0.2 \mathrm{mg}$ of antioxidant per gram of oil $[22,23]$. Each bottle was placed on a magnetic stirrer for $30 \mathrm{~min}$ to thoroughly mix the antioxidant and oil. The bottles were then placed in an incubator at $60{ }^{\circ} \mathrm{C}$ for $15 \mathrm{~d}$ to induce accelerated oxidation. $2 \mathrm{ml}$ aliquots were taken from each bottle every 3 days. The samples were analyzed for the PV, TBARS, CD and FFA to determine the effects of different types of antioxidants on the oxidation stability of tara seed oil $[24,25]$.

\section{PV}

The PV were measured according to the method of the AOAC [26], with slight modifications. Accordingly, the tara seed oil samples $(2 \mathrm{~g})$ were dissolved in $30 \mathrm{~mL}$ of a chloroform-glacial acetic acid (3:2, v/v) solution. Then, 1 $\mathrm{mL}$ of a saturated solution of KI was added. The mixture was shaken by hand for $1 \mathrm{~min}$ and then kept in dark for $5 \mathrm{~min}$. After the addition of $75 \mathrm{~mL}$ of distilled water, the mixture was titrated against sodium thiosulfate $(0.002$ $\mathrm{mol} / \mathrm{L}$ ) until the yellow color almost disappeared. Then, $0.5 \mathrm{~mL}$ of starch indicator solution was added. Titration was continued until the blue color disappeared. The blank was treated exactly like the samples. The PV (milliequivalents (meq) of peroxide per kilogram of oil, meq/ $\mathrm{kg}$ ) was calculated as follows:

$$
\mathrm{PV}(\mathrm{meq} / \mathrm{kg})=12.69 \times 78.8 \times \mathrm{C}(\mathrm{V} 1-\mathrm{V} 0) / \mathrm{m},
$$

where $\mathrm{C}$ is the concentration of sodium thiosulfate $(\mathrm{mol} / \mathrm{L})$; V1 and V0 are the volumes $(\mathrm{mL})$ of sodium thiosulfate used in the sample and blank titrations, respectively; and $\mathrm{m}$ is the mass ( $\mathrm{g}$ ) of tara seed oil.

\section{TBARS}

TBARS is defined as the quantity of malondialdehyde (in milligrams) present in $1 \mathrm{~kg}$ of sample, and is an index of lipid oxidation as measured by MDA content. TBARS were determined using a slight modification of the method by Zhang et al. [27]. Tara seed oil samples (2 g) were homogenized in $10 \mathrm{~mL}$ of a trichloroacetic acid (7.5\%) and EDTA (0.1\%) aqueous solution. The samples were shaken continuously for $30 \mathrm{~min}$ on a mechanical 
shaker and then filtered. Exactly $5 \mathrm{~mL}$ of the filtrate was added to $5 \mathrm{~mL}$ of 2-thiobarbituric acid $(2.88 \mathrm{~g} / \mathrm{L})$ solution, and then transferred to a $25-\mathrm{mL}$ colorimetric tube. The mixture was heated in a water bath at $90{ }^{\circ} \mathrm{C}$ for 40 min until a pink color developed. Then, the tube was cooled for $1 \mathrm{~h}$, and centrifuged for $5 \mathrm{~min}$ (room temperature). The supernatant was added to $5 \mathrm{~mL}$ of chloroform in another tube and then shaken. The mixture was left to stand for at least $1 \mathrm{~h}$, and then the absorbance was measured at $532 \mathrm{~nm}$ using a spectrophotometer (UV-2550, Shimadzu, City, Country). The TBARS content was calculated from a malondialdehyde (MDA) standard curve. The MDA solutions were freshly prepared by acidification of 1,1,3,3-tetraethoxypropane. The standard curve covered a concentration range of $0.02-0.3 \mu \mathrm{g} / \mathrm{mL}$, the results are expressed as milligrams of MDA per kilogram of the tara seed oil. The MDA concentration was calculated as follows:

$$
\operatorname{MDA}(\mathrm{mg} / \mathrm{kg})=\mathrm{S} / \mathrm{m} \times 10,
$$

where $\mathrm{S}$ is the mass concentration of MDA obtained from the standard curve, and $\mathrm{m}$ is the mass of squalene $(\mu \mathrm{g})$ in the sample.

\section{CD}

The CD content was measured using a slight modification of the method proposed by Leclerc et al. [28]. Oil samples $(0.02 \mathrm{~g})$ were diluted with isooctane, and the absorbance of each solution at $233 \mathrm{~nm}$ was determined against a blank of isooctane. The CD content was calculated from the absorbance and the final concentration of the sample as follows:

$$
\mathrm{CD}=\mathrm{A} / \mathrm{C} \times \mathrm{P},
$$

where $\mathrm{A}$ is the absorbance of the sample at $233 \mathrm{~nm}$; C is the final concentration of the sample after dilution (grams per $100 \mathrm{~mL}$ of isooctane); and $\mathrm{P}$ is the path length of the cell $(\mathrm{cm})$.

\section{FFA}

FFA determinations were performed according to the method of Zhang et al. [29], with some modifications. Oil samples $(3 \mathrm{~g})$ were dissolved in $50 \mathrm{~mL}$ of a mixture of neutral ether-ethanol $(1: 1, \mathrm{v} / \mathrm{v})$. The mixture was then shaken by hand. After cooling to room temperature, the mixture was titrated against potassium hydroxide $(0.01$ $\mathrm{mol} / \mathrm{L})$ using phenolphthalein $(10 \mathrm{~g} / \mathrm{L})$ as an indicator. The FFA value (meq $/ \mathrm{kg}$ ) was calculated as follows:

$$
\text { FFA }(\mathrm{mg} / \mathrm{g})=(\mathrm{V} \times \mathrm{C} \times 56.11) / \mathrm{m},
$$

where $\mathrm{V}$ is the volume of potassium hydroxide used in the titration with the samples $(\mathrm{mL}) ; \mathrm{C}$ is the concentration of potassium hydroxide $(\mathrm{mol} / \mathrm{L})$; and $\mathrm{m}$ is the mass of the tara seed oil (g) sample.

\section{Statistical analysis}

Statistical analyses (ANOVA) were performed using SPSS11.5 (Company name, City, Country). The results are expressed as the mean standard deviation. Results with $\mathrm{P}<0.05$ were considered significant. Each group experiment was repeated three times, and take the results were averaged results as the final experimental data.

\section{Results and discussion}

\section{Effect of CA on the PV}

Figure 1 shows the PV results for the tara seed oil samples with added CA20, CA60, CA99, BHA, BHT, and TBHQ were obtained after accelerated oxidation at $60^{\circ} \mathrm{C}$ (Fig. 1).

The PV for each tara seed oil increased as the length of storage increased, which resulted in production of more primary oxidation products (e.g. hydroperoxides). For the experimental control group without any antioxidant, the PV increased faster and reached a higher value $(163.1 \pm 0.35 \mathrm{meq} / \mathrm{kg})$ than the samples with antioxidants. Addition of one of the antioxidants (CA20, CA60, CA99, BHA, BHT, or TBHQ) decreased the PV. The PVs for CA20, CA60, CA99, BHA, BHT, and TBHQ were $90.1 \pm 0.61 \mathrm{meq} / \mathrm{kg}, 81.4 \pm 0.42 \mathrm{meq} / \mathrm{kg}, 62.0 \pm 0.31 \mathrm{meq} /$ $\mathrm{kg}, 136.5 \pm 0.55 \mathrm{meq} / \mathrm{kg}, 101.3 \pm 0.46 \mathrm{meq} / \mathrm{kg}$, and $(44.6 \pm 0.49) \mathrm{meq} / \mathrm{kg}$, respectively. Compared with the control group, the PV inhibition rates of the antioxidants CA20, CA60, CA99, BHA, BHT, and TBHQ were 44.8, $50.1,62.0,16.3,37.9$, and $72.7 \%$.

These results show that $\mathrm{CA}$ effectively inhibited oxidation of tara seed oil, and was a stronger antioxidant than BHA and BHT but a weaker antioxidant than TBHQ. The antioxidants could be arranged in order of antioxidant strength as follows: TBHQ > CA99 > CA60 > CA20 > BHA > BHT.

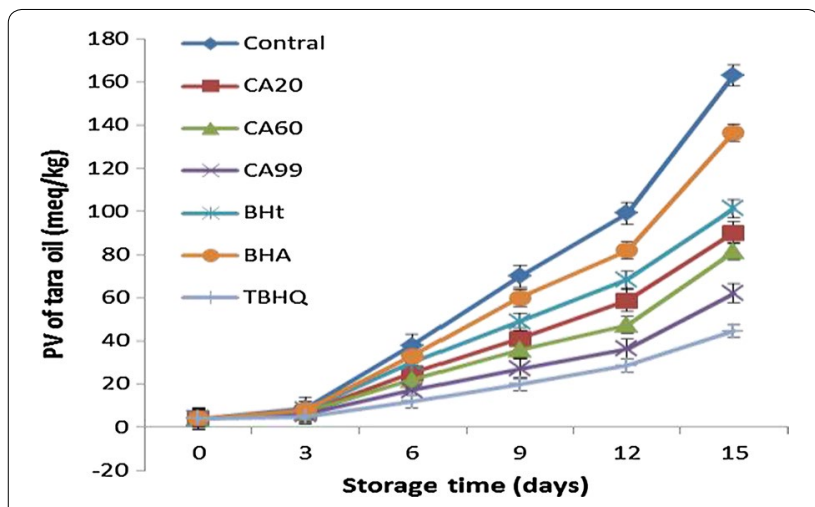

Fig. 1 PV results for tara seed oil samples after accelerated oxidation 


\section{Effect of CA on TBARS}

Lipid oxidation generates primary oxidation products, which reduce the stability of the product and can result in further oxidation and decomposition. Further oxidation generates secondary oxidation products, such as ketones, aldehydes, and acids. Among these secondary oxidation products is MDA, which can be detected by measuring the absorbance at $532 \mathrm{~nm}$ MDA can be generated during oil oxidation, and can be used as an indicator of rancidity.

The standard curve of MDA (Fig. 2) gave an equation of $\mathrm{y}=0.9233 \mathrm{x}+0.0387(\mathrm{R} 2=0.9995)$.

TBARS results were obtained for tara seed oil with the six antioxidants (Fig. 3).

Compared with the control group without antioxidant (TBARS $=0.26 \mathrm{e}$ of $1 \mathrm{meq} / \mathrm{kg}$ ), all the antioxidants reduced the TBARS. The TBARS results for CA20, CA60, CA99, BHA, BHT, and TBHQ were $0.14 \pm 0.004 \mathrm{meq} /$ $\mathrm{kg}, 0.122 \pm 0.005 \mathrm{meq} / \mathrm{kg}, 0.098 \pm 0.003 \mathrm{meq} / \mathrm{kg}$, $0.193 \pm 0.006 \mathrm{meq} / \mathrm{kg}, 0.178 \pm 0.005 \mathrm{meq} / \mathrm{kg}$, and $0.069 \pm 0.001 \mathrm{meq} / \mathrm{kg}$, respectively. The TBARS inhibition rates for CA20, CA60, CA99, BHA, BHT, and TBHQ were $46.2,53.1,62.3,25.8,31.5$, and $73.5 \%$, respectively.

These results show that $\mathrm{CA}$ is an effective antioxidant for reducing oxidation of tara seed oil. Compared with the other antioxidants, CA was stronger than BHA and BHT but weaker than TBHQ. The antioxidants could be arranged in order of antioxidant strength as follows: TBH $\mathrm{Q}>\mathrm{CA} 99>\mathrm{CA} 60>\mathrm{CA} 20>\mathrm{BHA}>\mathrm{BHT}$.

\section{Effect of CA on CD}

The CD content is frequently used as an indicator of hydroperoxide content, as proposed by Lecomte J et al. Most hydroperoxides formed through oxidation of unsaturated fatty acids are conjugated dienes. Formation of hydroperoxides stabilizes the radical state through formation of the double bond, which absorbs in the UV region (235 nm). The CD content is an indicator of the oxidative state of an oil, and of the effectiveness of an antioxidant.

CD results were obtained for tara seed oil CD (Fig. 4).

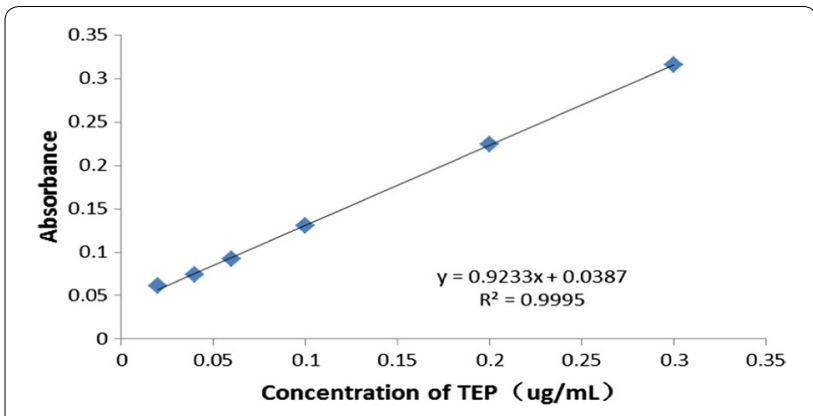

Fig. 2 MDA standard curve

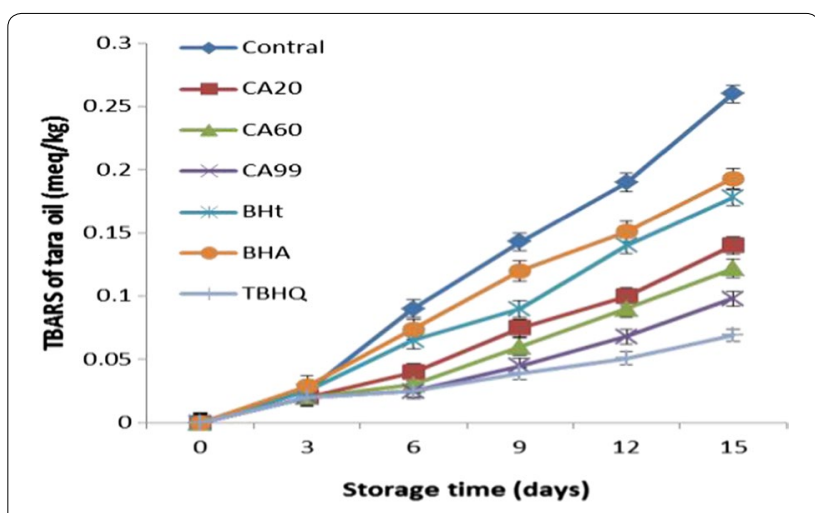

Fig. 3 TBARS results for tara seed oil samples after accelerated oxidation

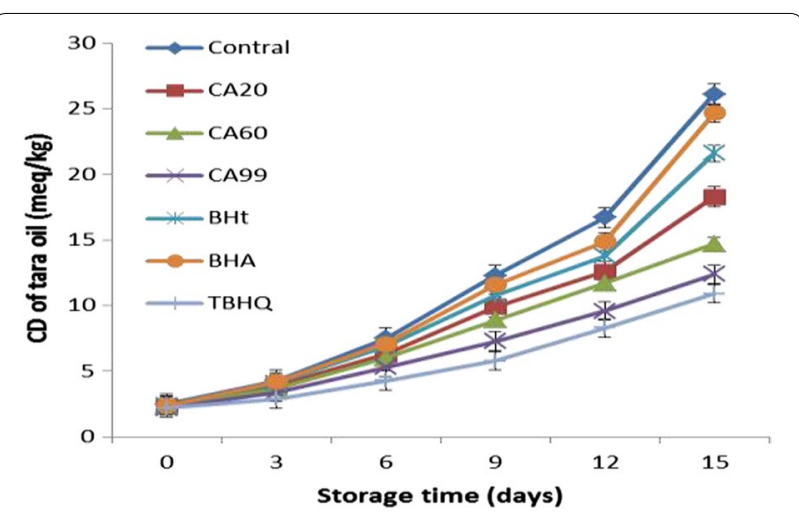

Fig. 4 CD results for tara seed oil samples after accelerated oxidation

Compared with the control group, all the antioxidants improved the stability of tara seed oil to oxidation. The control group had a CD value of $26.1 \pm 0.02$ at 15 days. The $\mathrm{CD}$ values at 15 days for the samples with CA20, CA60, CA99, BHA, BHT, and TBHQ were $18.3 \pm 0.01$, $14.7 \pm 0.005,12.4 \pm 0.021,24.7 \pm 0.015,21.6 \pm 0.02$, and $10.9 \pm 0.017$, respectively. The inhibition rates for $C D$ content for CA20, CA60, CA99, BHA, BHT, and TBHQ were $29.9,43.7,52.5,5.4,17.2$, and $58.2 \%$, respectively.

These results show that CA is a good antioxidant for tara seed oil. Compared with the other antioxidants, CA is stronger than BHA and BHT, and weaker than TBHQ. The antioxidants could be arranged in order of antioxidant strength as follows: TBHQ $>$ CA99 > CA60 > CA20 $>$ BHA $>$ BHT.

\section{Effect of CA on FFA}

Temperature, light, and other factors can cause oil oxidation, which generates both primary and secondary oxidation products. During oil degradation, triglyceride hydrolysis, which forms FFAs, and fatty acid dissociation occur. The FFA content can be used to determine the degree of oil oxidation. 


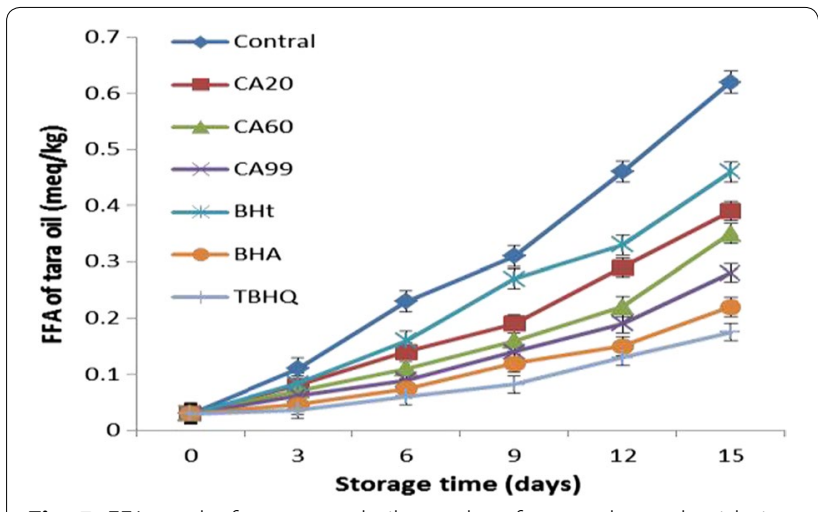

Fig. 5 FFA results for tara seed oil samples after accelerated oxidation

FFA results were obtained for tara seed oil (Fig. 5).

Compared with the control group without antioxidant (15-day FFA $=0.62 \pm 0.04 \%$ ), all of the antioxidants decreased the FFA content. For CA20, CA60, CA99, BHA, BHT, and TBHQ the 15-day FFA results were $0.39 \pm 0.04 \%, 0.35 \pm 0.354 \%, 0.28 \pm 0.284 \%$, $0.22 \pm 0.224 \%, 0.46 \pm 0.464 \%$, and $0.175 \pm 0.05 \%$, respectively. The FFA inhibition rates of CA20, CA60, CA99, BHA, BHT, and TBHQ were 37.1, 44.0, 55.0, 65.0, 26.0, and $72.0 \%$, respectively.

These results show that CA is a good antioxidant for tara seed oil. Compared with the other antioxidants, $\mathrm{CA}$ is stronger than BHA and BHT, and weaker than TBHQ. The antioxidants can be arranged in order of antioxidant strength as follows: TBHQ > CA99 > CA60 > CA20 > BHA > BHT.

\section{Conclusions}

The antioxidant strength of CA was compared with synthetic antioxidants by adding CA20, CA60, CA99, BHA, BHT, and TBHQ to tara seed oil and exposing the samples to accelerated oxidation conditions. Analysis of oxidation indicators, including PV, TBARS, CD content, and FFA content, was used to determine the effect of each antioxidant. The results on the last day of accelerated oxidation (day 15) were compared, and showed that CA was a stronger antioxidant than the synthetic antioxidants. In order of antioxidant strength, the antioxidants were TBH $\mathrm{Q}>\mathrm{CA} 99>\mathrm{CA} 60>\mathrm{CA} 20>\mathrm{BHA}>\mathrm{BHT}$. Therefore, $\mathrm{CA}$ could be used to replace synthetic antioxidants, and will likely be safer for human consumption and the environment because of its lower toxicity.

\section{Authors' contributions}

ZL, LY contributed equally to performing the research, analyzing the data, and writing the manuscript. FY and $Y Z$ approved the final manuscript. All authors read and approved the final manuscript.

\section{Author details}

1 Key Laboratory of Forest Plant Ecology, Ministry of Education, Northeast Forestry University, Harbin 150040, China. ${ }^{2}$ Yichun Academy of Forestry, Yichun, Heilongjiang Province 153000, China.

\section{Acknowledgements}

This work was supported by the Forestry Industry Research Special Funds for Public Welfare Projects of China (Grant No. 201404616).

\section{Competing interests}

The authors declare that they have no competing interests.

\section{Consent for publication}

All authors consent to the publication.

Ethics approval and consent to participate

Not applicable.

\section{Publisher's Note}

Springer Nature remains neutral with regard to jurisdictional claims in published maps and institutional affiliations.

Received: 30 August 2017 Accepted: 12 February 2018

Published online: 04 April 2018

\section{References}

1. Skowyra M, Falguera V, Gallego G, Peiró S, Almajano MP (2014) Antioxidant properties of aqueous and ethanolic extracts of tara (Caesalpinia spinosa) pods in vitro and in model food emulsions. J Sci Food Agric 94(5):911-918

2. Li ZJ, Zhang L, ZU YG, Yang FJ (2015) Tara oil extraction by supercritical carbon dioxide and its quality analysis. Bull Bot Res 35(3):467-470

3. Reddy LH, Couvreur $P$ (2009) Squalene: a natural triterpene for use in disease management and therapy. Adv Drug Deliv Rev 61:1412-1426

4. Shiota M, Konishi H, Tatsumi K (1999) Oxidative stability of fish oil blended with butter. J Dairy Sci 82:1877-1881

5. Laguerre M, Lecomte J, Villeneuve P (2007) Evaluation of the ability of antioxidants to counteract lipid oxidation: existing methods, new trends and challenges. Prog Lipid Res 46:244-282

6. Zutaa PC, Simpsona BK, Zhao X (2007) The effect of a-tocopherol on the oxidation of mackerel. Food Chem 100(2):800-807

7. Trevisan M, Browne R, Ram M et al (2001) Correlates of markers of oxidative status in the general population. Am J Epidemiol 154:348-356

8. Frutos M, Hernandez-Herrero JA (2005) Effects of rosemary extract (Rosmarinus officinalis) on the stability of bread with an oil, garlic and parsley dressing. LWT 38:651-655

9. Gharby S, Harhar H, Guillaume D, Haddad A, Matthaus B, Charrouf Z (2011) Oxidative stability of edible argan oil: a two-year study. LWT Food Sci Technol 44:1-8

10. Balasundram N, Sundram K, Saman S (2006) Phenolic compound in plants and agri-industrial by-products: antioxidant activity, occurrence, and potential uses. Food Chem 99:191-203

11. Chen XQ, Zhang Y, Zu YG, Yang L, Qi L, Wang W (2014) Antioxidant effects of rosemary extracts on sunflower oil compared with synthetic antioxidants. Food Sci Technol 9:385-391

12. Wang H, Yang L, Zu YG, Liu F, Liu TT (2011) Comparative effect of carnosic acid, BHT and a-tocopherol on the stability of squalene under heating and UV irradiation. Food Res Int 44:2730-2734

13. Wang H, Liu F, Yang L, Zu YG, Wang H, Qu SZ, Zhang Y (2011) Oxidative stability of fish oil supplemented with carnosic acid compared with synthetic antioxidants during long-term storage. Food Chem 128:93-99

14. Frankel EN, Huang SW, Prior E, Aeschbach R (1996) Evaluation of antioxidant activity of rosemary extracts, carnosol and carnosic acid in bulk vegetable oils and fish oil and their emulsions. J Sci Food Agric 72:201-208

15. Salariya AM, Rehman Z (2006) Effect of synthetic antioxidants on storage stability of Khoa-a semi-solid concentrated milk product. Food Chem 96:122-125

16. Wang L, Yang B, Yan B, Yao X (2012) Supercritical fluid extraction of astaxanthin from Haematococcus pluvialis and its antioxidant potential in sunflower oil. Innov Food Sci Emerg Technol 13:120-127

17. Hras AR, Hadolin M, Knez Z, Bauman D (2000) Comparison of antioxidative and synergistic effects of rosemary extract with a-tocopherol, 
ascorbylpalmitate and citric acid in sun flower oil. Food Chem 71:229-233

18. Iqbal S, Bhanger MI (2007) Stabilization of sunflower oil by garlic extract during accelerated storage. Food Chem 100(1):246-254

19. Chen XQ, Zhang Y, Zu YG (2014) Antioxidant effects of rosemary extracts on sunflower oil compared with synthetic antioxidants. Int J Food Sci Technol 49:385

20. Goli AH, Barzegar M, Sahari MA (2005) Antioxidant activity and total phenolic compounds of pistachio (Pistachia vera) hull extracts. Food Chem 92:521-525

21. Nissen LR, Mansson L, Bertelsen G, Huynh-Ba T, Skibsted LH (2000) Protection of dehydrated chicken meat by natural antioxidants as evaluated by electron spin resonance spectrometry. Journal of Agricultural and Food Chemistry 48:5548-5556

22. Duh PD, Yen GC (1997) Antioxidant efficacy of methanolic extracts of peanut hulls in soybean and peanut oils. J Am Oil Chem Soc 74:745-748

23. GB 2760-2007 (2007) Hygienic standards of uses of food additives. China
24. Bubonja-Sonje M, Giacometti J, Abram M (2011) Antioxidant and antilisterial activity of olive oil, cocoa and rosemary extract polyphenols. Food Chem 127:1821-1827

25. A.O.A.C. (1990) Official methods of analysis, 15th edn. Association of Official Analytical Chemists, Washington

26. Zhang Y, Yang L, Zu YG, Chen XQ, Wang FJ, Liu F (2010) Oxidative stability of sunflower oil supplemented with carnosic acid compared with synthetic antioxidants during accelerated storage. Food Chem 118:656-662

27. Mlakarl A, Spiteller G (1996) Previously unknown aldehydic lipid peroxidation compounds of arachidonic acid. Chem Phys Lipid 79:47-53

28. Shahidi F, Wanasundara UN (1998) Methods of measuring oxidative rancidity in fats and oils. In: Akoh CC, Min DB (eds) Food lipids, chemistry, nutrition, and biotechnology. CRC Press, Boca Raton, pp 377-396

29. Nogala-Kalucka M, Korczak J, Dratwia M, Lampart-Szczapa E, Siger A, Buchowski M (2005) Changes in antioxidant activity and free radical scavenging potential of rosemary extract and tocopherols in isolated rapeseed oil triacylglycerols during accelerated tests. Food Chem 93:227-235

\section{Submit your manuscript to a SpringerOpen ${ }^{\odot}$ journal and benefit from:}

- Convenient online submission

- Rigorous peer review

- Open access: articles freely available online

- High visibility within the field

- Retaining the copyright to your article

Submit your next manuscript at $\boldsymbol{\nabla}$ springeropen.com 